\title{
A predictive model for hydrogen content in steel in non-degassed heats
}

\author{
Beatriz de Paula Lopes ${ }^{1 *}$ (1) \\ José Adilson de Castro ${ }^{1}$ \\ Leonardo Martins Demuner ${ }^{2}$ \\ André Luiz Vasconcellos da Costa e Silva ${ }^{3}$
}

\begin{abstract}
Hydrogen may cause several problems during steel processing. Issues caused or enhanced by hydrogen range from different types of bubbles such as pinholes to breakout during continuous casting. Further down the line, segregation and embrittlement may lead to cracking such as flaking or blistering. These problems impact plant productivity and have cost impacts on equipment maintenance and the need for additional steel treatment. Some of the problems lead to scraping. Although vacuum degassing effectively controls the hydrogen content of steel, it introduces additional costs that are not justifiable for many products. This work aims to identify the main sources of hydrogen in liquid steel in the Ternium Brazil steelmaking plant and to propose a model to decide the need for hydrogen measurement for the degassing process, focusing on steels for which vacuum degassing is not a specification requirement. It is essential for these steels to guarantee a controlled level of dissolved hydrogen to avoid problems, mostly at casting. Once the sources are identified, a model is developed to predict the hydrogen content at the beginning of the secondary metallurgy treatment. Based on the model, it is proposed that hydrogen should be measured or not at this step to decide if vacuum degassing is required to assure safety in casting.
\end{abstract}

Keywords: Hydrogen; Steel; Steel plant.

\section{Introduction}

The solubility of hydrogen in iron varies with temperature and with phase transformations, as shown in Figure 1. In general, there is good agreement between the various published values of the solubility of hydrogen in steel [1-3].

However, the hydrogen content in the atmosphere is only around $0,6 \mathrm{ppm}$ [4]. It has been well established that the main source of hydrogen in steel is the reduction of water, normally present as humidity [5-7], in accordance with Equation 1. This will be discussed in more detail in the next section.

$$
\mathrm{H}_{2} \mathrm{O}=2 \underline{H}+\underline{O}
$$

The high mobility of hydrogen atoms in steel causes very fast redistribution and segregation during phase change (e.g. [8]). It has been established that the change in solubility during the $L \rightarrow \delta$ transformation is important to the formation of pinholes and similar defects during solidification $[9,10]$. Currently, this is relatively well modelled [11]. The diffusion of hydrogen through $\delta$, in the early stages of continuous casting seems to play an important role in the occurrence of breakout in continuous casting of steels containing somewhere over 6-8ppm hydrogen [12,13]. Apparently, a larger volume of hydrogen diffuses through the initial thin layer of solid steel than is retained in pinholes or bubbles in general [14] influencing heat transfer, powder behaviour and eventually leading to breakouts. This is a cause of concern in many steel mills $[12,13,15]$. Further down in the processing route, hydrogen may cause cracks, blisters [16] and flakes [17]. These phenomena are mostly associated with the combination of transformation stresses, alloying element segregation and hydrogen redistribution and are well understood [17-19], albeit they continue to be hard to control in many industrial situations. Hydrogen absorption during application and problems caused by it is also a very important problem [20], but this is not discussed here.

Since the 1950's the classical solution to control hydrogen content in steelmaking is vacuum degassing $[18,21]$. This solution, however, introduces significant additional costs. Thus, it should be limited to essential cases. The introduction of "Sieverts' Law-based" fast and reliable analysis of hydrogen (pioneered by HYDRIS ${ }^{\circledR}[22]$ ) made possible

${ }^{l}$ Programa de Pós-graduação em Engenharia Metalúrgica - PPGEM, Universidade Federal Fluminense - UFF, Volta Redonda, RJ, Brasil.

${ }^{2}$ Ternium Brasil, Rio de Janeiro, RJ, Brasil.

${ }^{3}$ Escola de Engenharia Industrial Metalurgica de Volta Redonda - EEIMVR, Universidade Federal Fluminense - UFF, Volta Redonda, RJ, Brasil.

*Corresponding author: beatriz.pls@hotmail.com 
the rapid analysis of hydrogen during steelmaking. This can be used as a decision tool concerning further processing of heats. However, this analysis also introduces a significant cost to the process.

Currently, Ternium systematically vacuum treats steels in which this is essential either because of client specification, chemical composition, final product thickness or application. For other steels, hydrogen is determined at the beginning of the secondary metallurgy step and, should it exceed a defined threshold, the heat is degassed regardless of other requirements.

Understanding the sources of hydrogen in the process as well as how hydrogen is absorbed or removed in processing steps in the melt shop can help reduce some of the costs in this process. Two strategies have been followed in steel plants to prevent hydrogen problems while controlling processing cost: (a) Evaluating the sources of hydrogen in the steelmaking process (e.g. [6,7,10,23-25]); (b) creating models to estimate the hydrogen content at some step of the melt shop process (e.g. [13,26,27]). These strategies may be combined. In the present case, we followed the combined approach: by identifying the most relevant sources of hydrogen in the steel when it reaches the secondary metallurgy, qualitative and semi-quantitative control measures can be proposed in raw materials and processing to prevent high hydrogen contents. The identification step is also relevant in helping defining which phenomena are relevant to be worth modeling. We opted for kinetic models of some stages of the process, as opposed to using artificial intelligence, neural network and other efficient fitting tools. It was felt that by adhering to

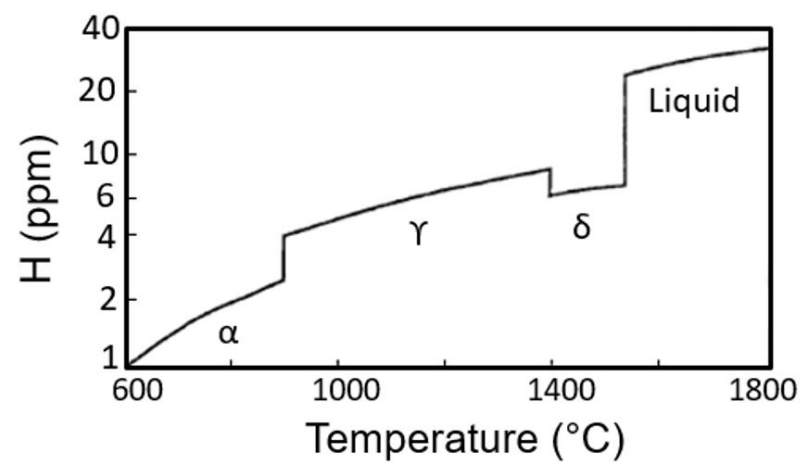

Figure 1. Solubility of hydrogen in iron (and low alloy steels) at 1atm as a function of temperature. Adapted from Turkdogan [1]. fundamentals, extrapolation to new conditions would be more reliable. The main objective of the work was then twofold: indicate process steps/materials that are more relevant for hydrogen pickup at Ternium and propose a model that could reduce the need for analyzing the hydrogen of all heats when they reach secondary metallurgy. The combination of these two measures should reduce processing costs by reducing the number of heats with excessive hydrogen content and reducing the number of heats that must be analyzed to decide if they should be degassed or not.

\section{Hydrogen sources}

As the absorption of hydrogen in steel occurs in accordance with Equation 1, water, water vapour and humidity are fundamental concerns during steelmaking when hydrogen control is considered. In some cases, like oil contamination in scrap and coke additions, hydrogen may be present in a non-oxidized formed. And in ferro-alloys, besides humidity, dissolved hydrogen is also present as will be discussed. Numerous sources of water and hydrogen must be considered in the melt shop. In this study, we consider sources in steps from converter charging until the start of ladle metallurgy, as indicated in the schematic meltshop flow of Figure 2.

Many authors have evaluated the different sources of hydrogen in steelmaking, and their relevance [5-7,10,23,24,28]. Their relative influences, however, change in different plants, based on process conditions. One can group the sources as metallic charge, refractories, gases (including air) and additions during the process.

Metallic charge: hot metal, scrap.

Refractories [29]: proper drying and outgassing of refractories (and their repairs): converter, ladle, tundish, entry nozzle, submerged tube [25]

Gases: purity of oxygen, bottom gas blown in converter, humidity in the air (on top of steel in converter, ladle and tundish) and entrained during exposed pouring operations [27].

Additions: lime and other slag forming additions, ferroalloys, coke, metallic additions including wires, cover powders in tundish and mould [28].

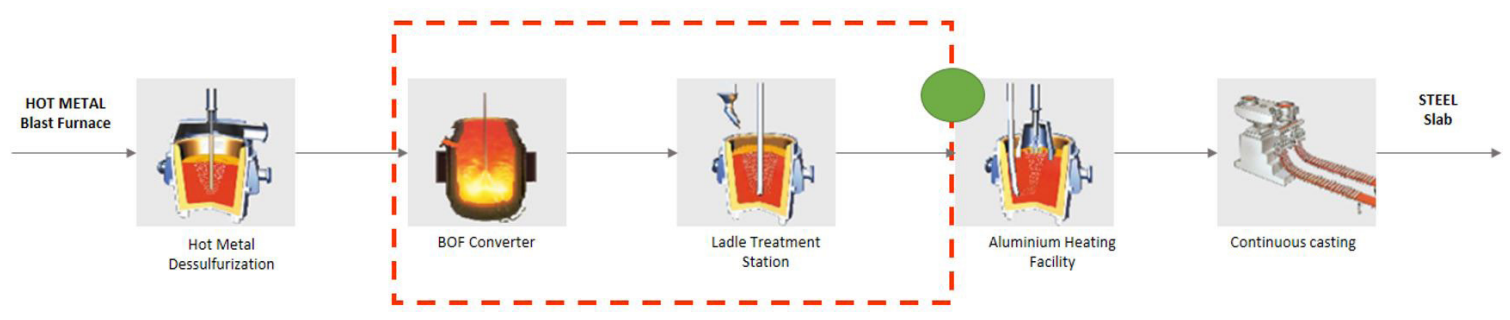

Figure 2. Steel production flow for a non-vacuum treated steel at Ternium, highlighting steps considered in this study. The green dot indicates the point where $\mathrm{H}$ is currently measured at Ternium, to decide if the heat must be degassed for casting safety. 
Equation 1 clearly indicate that the more deoxidized the steel, for the same $\mathrm{H}_{2} \mathrm{O}$ potential, more hydrogen may be absorbed until equilibrium is reached. High oxidations somewhat "protects" the steel from excessive hydrogen absorption (e.g. [30]). Hydrogen may even be oxidized out, depending on the thermodynamic conditions.

Furthermore, as will be discussed in the next section, the vigorous gas evolution during converter steelmaking tends to indicate that the later additions are made, the more critical their hydrogen content might be.

Thus, one can expect that sources that are closer to the end of the investigated process (Figure 2) will be more relevant than those occurring earlier in the process will.

\subsection{Lime}

As burnt lime is very hygroscopic and lime is used in substantial quantities in basic steelmaking, it has been one of the raw materials most closely scrutinized [31,32]. In general, most steel plants are very careful with controlling humidity in lime at reception and during stocking. The fact that the absorption of humidity affects lime reactivity is also a reason for the importance of this control.

According to Fruehan and Misra [28] due to the moist atmospheric conditions, lime can become hydrated to form calcium hydroxide. This hydrated lime when added to the liquid melt heats up and decomposes according to the Equation 2.

$$
\mathrm{Ca}(\mathrm{OH})_{2(s)}=\mathrm{CaO}_{(s)}+\mathrm{H}_{2} \mathrm{O}_{(g)}
$$

This water vapor dissociates close to the steel and $\mathrm{H}$ can be absorbed following Equation 1 .

Fruehan and Misra [28] found that close to $2 \%$ of the hydrogen added in the form of $\mathrm{Ca}(\mathrm{OH})_{2}$ was absorbed in the liquid steel. They considered that maximum pickup scenario would be when all the lime added during steelmaking is hydrated and all hydrogen is absorbed. The maximum amount of hydrogen picked up would be given according to Equation 3.

$$
\Delta H_{\text {lime }}=\frac{2 \times 2 \times W_{\text {lime }}}{74 W_{\text {steel }}} 10^{4}, \mathrm{ppm}
$$

Where,

$W_{\text {lime }}$ : weight of lime $(\mathrm{kg})$;

$W_{\text {steel }}$ : weight of liquid metal $(\mathrm{kg})$;

74 and 2: $\mathrm{Ca}(\mathrm{OH})_{2}$ and $\mathrm{H}_{2}$ molecular masses, respectively $(\mathrm{kg} / \mathrm{kmol})$.

\subsection{Ferro-alloys and metallic additions}

Hydrogen and moisture content in cooling additions (scrap or ore) and ferro-alloys may cause hydrogen pickup into liquid steel. Moisture content in materials is greatly influenced by its transport and storage conditions, whereas dissolved hydrogen, in special in ferro-alloys is related to their manufacture process. Wire additions can be essentially hydrogen free (e.g. Aluminium wire) or may be subjected to humidity absorption, when granular materials are present. Several researchers have tried to determine typical values for the hydrogen content in each type of ferro-alloy. Silveira et al. [33] related the of hydrogen contents of some types of ferro-alloys. There is a considerable scatter, but simple mass balances indicate that these contents are not relevant for the total hydrogen content in low alloy steel. This is confirmed by Ootsuka et al. [34].

\subsection{Coke}

Coke may contain humidity and hydrogen bonded as hydrocarbons. Both these sources are relevant to hydrogen pickup into liquid steel. Depending on the coking process and degree of coking the content of hydrocarbons may be significant and some cokes have a complex pore structure [34]. It is not uncommon in steelmaking plants to term all non-graphite carbon-rich sources or carbon as "cokes". This can be misleading as petroleum coke may contain $3.5 \%$ hydrogen (without considering eventual humidity) [35]. Fruehan and Misra [28], evaluated the effects of metallurgical coke and petroleum coke additions and observed significant hydrogen pickup. This is in accordance with the observations of [34] who did not specify the type of carbonaceous addition. Jha et al. [36] stressed the importance of the use of low $\mathrm{H}$ pet coke. The industrial results of Ootsuka et al. [34] and of the plant trials of Fruehan and Misra are consistent.

A recovery of 8 to $12 \%$ was observed in Fruehan and Misra experiments on hydrogen pickup from petroleum coke assuming a hydrogen content of $1 \%$ in the coke. They proposed that it is reasonable to assume that close to $10 \%$ of the hydrogen present in the form of impurity in the coke is absorbed into liquid steel [28]. Thus the hydrogen pickup from coke additions would be given as:

$$
\Delta H_{\text {coke }}=\frac{10 H_{\text {coke }} W_{\text {coke }}}{100 W_{\text {steel }}} 10^{4}, \text { ppm }
$$

Where,

$H_{\text {coke }}$ : coke's hydrogen content (\%);

$W_{\text {coke }}$ : coke added mass $(\mathrm{kg})$.

\subsection{Atmosphere moisture}

Slags are not perfect barriers to hydrogen. It has been shown that hydrogen can diffuse through slags. In basic slags the common ion is hydroxyl $\left(\mathrm{OH}^{-}\right)$and in acid slags water can break the silicate network bonding to silica tetrahedra [37,38]. The higher the basicity, the higher the concentration of hydroxyl in equilibrium with a given $\mathrm{H}_{2} \mathrm{O}$ pressure and hence higher solubility and diffusivity, all other factors constant.

Thus, atmospheric moisture can either be transferred through the slag or be directly absorbed when the metal is exposed to air, such as during transfer operations. When 
slag making additions are dry the slag is a good barrier to the absorption $[5,30]$. It has been well established that hydrogen pickup depends on the partial atmospheric water vapour pressure. Ternium plant is located in a region where high relative humidity is almost constant $80 \pm 8 \%$ as opposed to plants in temperate regions (e.g. 50-80\% in Tokyo) [39].

\section{Kinetics of hydrogen absorption and removal}

Heterogeneous processes in steelmaking, such as the absorption or removal of hydrogen are often limited by transport kinetics as the chemical reactions' are fast at refining temperatures [38]. Interfacial phenomena may play a role in these processes, as demonstrated by Belton for nitrogen, for instance [40].

Boorstein and Pehlke [41] studied the kinetics of absorption of hydrogen in steel and observed that it was transport controlled. No influence of surface active elements was observed. Small et al. [42] observed some effect of dissolved oxygen, which they ascribed to surface effects. Suzuki and Taniguchi [43] confirmed that mass transfer was the dominant phenomenon in the removal of hydrogen in steel. Their results concerning absorption were not conclusive. Sasaki and Belton [44] evaluated the decarburization of steel in $\mathrm{H}_{2} \mathrm{O} / \mathrm{CO}_{2}$ atmospheres and proposed that the water gas reaction may be influenced by surface active elements. In the present study, we decided to assume that the rate controlling step in absorption and removal of hydrogen from steel is transport, either in the liquid metal or in the gaseous species. Most of the industrial studies of the kinetics of the removal of hydrogen from steel was performed in vacuum degassing processes (e.g. [45-49]). Absorption in the tundish [27] and processes in the mould [12] were also modelled. Except in vacuum degassing modelling, interactions between gas and metal in steelmaking in general focuses in nitrogen and oxygen.

The rinsing effects of the large volume of $\mathrm{CO}$ evolution in the converter and in the electric arc furnace are useful tools for the removal of dissolved gases. Kempken [50] and Kempken and Pluschkell [51] developed a successful model to describe the behaviour of nitrogen in a combined blown converter. They confirmed the rinsing associated with the oxygen blow stage and the importance of the switch point between nitrogen and argon in bottom blowing.

In bottom blown converter, when hydrocarbons are used for tuyère cooling, models have been formulated to quantify the hydrogen pickup [52-54]. The model results [52] show that mass transfer is the controlling step and the partial pressure of hydrogen in the total gas defines the driving force for absorption.

Oxidation of the melt further promotes hydrogen elimination in accordance to Equation 1. At the end of oxygen blow in converter values close to $1 \mathrm{ppm}$ are reported. (eg $[6,23,33]$.
Most studies of gas pickup during tapping are related to reoxidation [55-58]. These studies show that the gas entrained by the jet impinging on the liquid metal surface on the ladle is a more relevant contribution to the pick-up than the reaction of the exposed jet with the atmosphere. This was the premise adopted by Braga and Tavares [27] when modeling hydrogen pickup in the tundish.

Unless interface phenomena or chemical reactions are involved, it is usually possible to use simple solutions to approximate mass transfer controlled problems. These involve formulating flow equations in or out of phases and the appropriate mass balances. If the transport in one phase controls the overall process, the driving force is obtained directly using the concentration in equilibrium with the other phase as the interface concentration.(e.g. $[38,59,60])$. Thus, in this situation, the hydrogen flux can be expressed as shown in Equation 5:

$$
j_{H}=k_{H}\left(\% H(t)-\% H_{e q}\right)
$$

Where,

$j_{H}$ : hydrogen mass flow per area per unit time;

$k_{H}$ : mass transfer coefficient;

$\% H_{e q}: H$ content in steel in equilibrium at the interface with, for instance, the gas phase;

$\% H(t)$ : H content in steel (bulk) at time t.

Performing a mass balance in the liquid metal phase, a "first order" kinetic equation is obtained [61]. The same form of equation is obtained if transport in the gas is the controlling step. So, this is a useful and practical approach for industrial use but may not always bring insights on the exact mechanism or even on process controlling step.

\section{Results and discussion}

The main factors that may be relevant to the hydrogen content in steel as it reaches the sampling point (green dot in Figure 2) were identified based on the analysis presented in the previous discussion. Furthermore, steps where time, agitation and exposure to atmosphere are important variables were also identified to determine the relevant hydrogen sources and pickup processes at Ternium. Based on the identification of potential variables, the data of around 4000 heats, from a period of 2 years was collected. This data was subjected to a statistical analysis to identify possible correlations with the hydrogen content measured by sensor at the sampling point (Figure 2). The values of the calculated correlation coefficients $r$ are shown in Figure 3. The values of $r$ are relatively low. Hence, not a single factor can explain to a large extent, the value of the final hydrogen content [62]. This is not surprising, since it is expected that many factors influence the final hydrogen content and that their influence may be a result of the combination of some factors [62]. The following were identified as the more relevant steps and additions, based on this statistical analysis: (a) heats with additions after sub-lance 
measurement (b) additions of carburizing agent (c) the tapping operation variables (time, oxidation...).

Thus, a model was formulated to predict the evolution of the $\mathrm{H}$ content along a heat up to the sampling point (Figure 2). The following assumptions were made:

(a) all normal blown heats would reach the same value of hydrogen at the moment of the sub-lance measurement. This value is unknown and is a parameter of the model;

(b) Additions performed after the sub-lance measurement will have a hydrogen yield that is the same for all additions. This yield is also a parameter of the model;

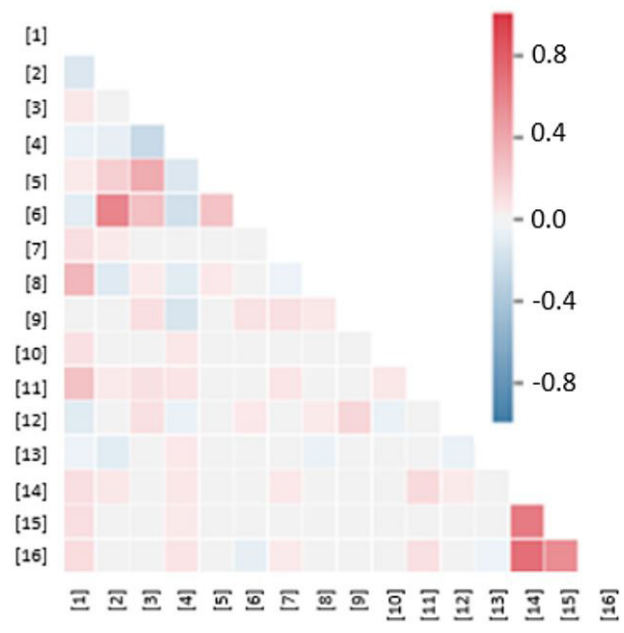

(c) For heats which incorporate hydrogen because of post sub-lance additions, the mixed blow after these additions promotes some hydrogen removal, depending on blow time. The kinetic model of this step must also be adjusted in the model;

(d) Additions performed during tapping will have a hydrogen yield that depends of the additions. These yields are also a parameter of the model;

(e) Finally, hydrogen is absorbed from air during tapping, depending on the stirring energy of tapping. The kinetic parameters for this step are also adjusted in the model.

Figure 4 presents an overview of the steps of the model.
[1] H AHF (ppm)
[2] Scrap total (t)
[3] Lime + DolLime+ Dol before sub-lance $(t)$
[4] FeSi + quartz before sub-lance (t)
[5] 02 blowing time ( $\mathrm{min})$
[6] 02 blowing $\left(\mathrm{Nm}^{3}\right)$
[7] 02 reblowing $\left(\mathrm{Nm}^{3}\right)$
[8] Additions after sub-lance ( $\mathrm{t}$ )
[9] Carbon endblow (\%)
[10] Relative humidity (\%)
[11] Tapping additions (t)
[12] Tapping time (min)
[13] Transport time LTS-AHF (min)
[14] Ar blowing time LTS ( $\mathrm{min}$ )
[15] Additions LTS ( $t$ )
[16] Treatment time LTS (min)

Figure 3. A color coded plot ("heatmap") of the calculated correlation coefficients, $r$ between selected steelmaking variables. Relevant variables are those that show some correlation to the value of H AHF (ppm), the hydrogen content measured at the start of ladle metallurgy.

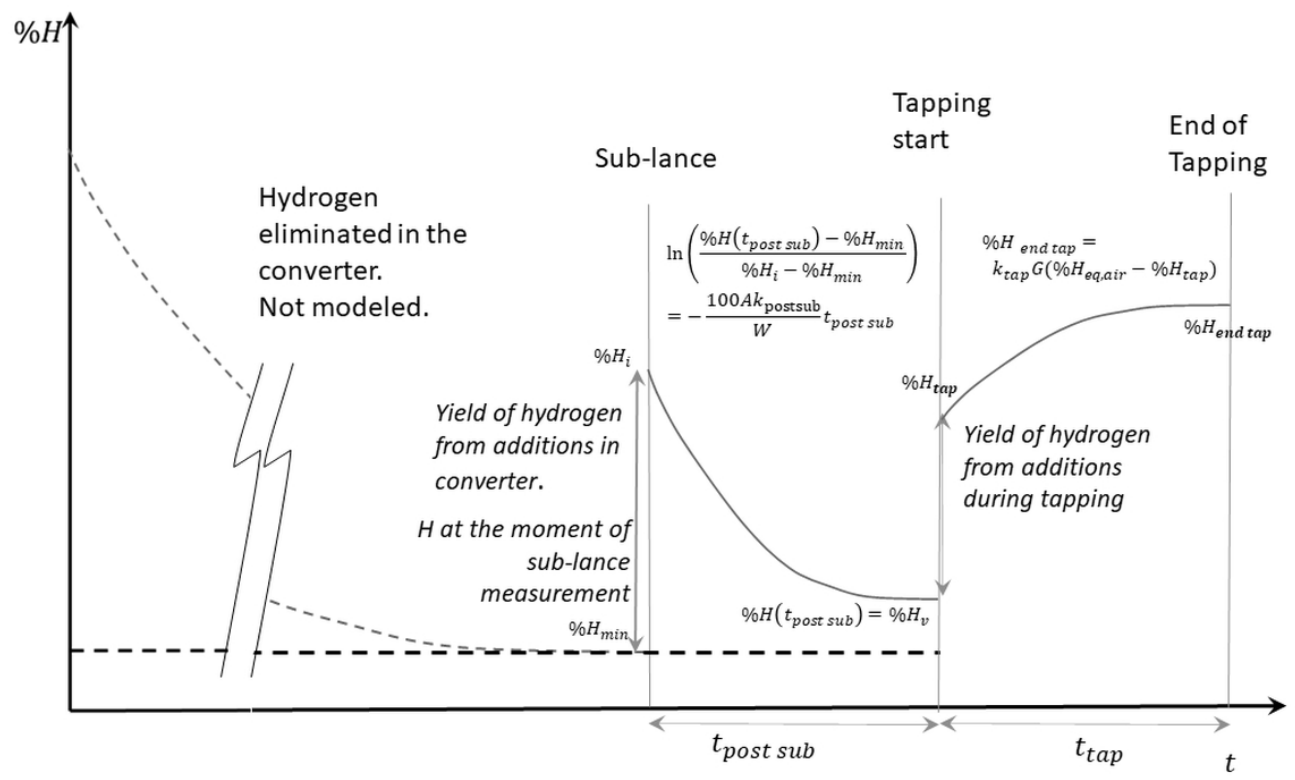

Figure 4. Schematic evolution of hydrogen in the steelmaking process, according to the formulated model. See text for discussion. 
These steps, together with the relevant parameters are discussed below.

\subsection{Hydrogen content at the sub-lance measurement}

As discussed in Section 3 was assumed that the strong evolution of $\mathrm{CO}$ and bottom stirring gas lowers the $H$ content significantly until the point when sub-lance measurement is made. Thus, it was assumed that all heats will have the same content of hydrogen at the moment of sub-lance measurement. This value, $\% H_{\min }$ is an adjustable parameter of the model. Should there be no addition to the metal after the sub-lance measurement, this will be the value of the hydrogen in the metal just before tapping.

\subsection{Hydrogen pickup from post-sub-lance additions}

After the sub-lance measurement, it may be necessary to add lime and/or coolants (sinter, DRI briquette or pellets). As the heat is oxidized at this moment, the pick-up of hydrogen is limited by the equilibrium value of Equation 1, considering the water vapour pressure as the value derived from air humidity and the oxygen content from the sub-lance measurement (or estimated from the apparent equilibrium with measured $\% \mathrm{C}$ in the converter). An average temperature of $1615^{\circ} \mathrm{C}$ was adopted at the time of the sub-lance measurement, according to plant average data.

Was assumed that the absorption efficiency of the humidity contained in these additions is affected also by the degree of oxidation of the bath, which controls the driving force for absorption. Hence, we introduce factor to limit hydrogen yield. Since:

$$
\% C x \% O=k(T)
$$

Equation 1 can be combined to Equation 6 to obtain Equation 7:

$$
\% H^{2} \frac{k}{\% C}=k_{l}
$$

And hence, Equation 8:

$$
\% H=K^{\prime} \sqrt{\% C_{\text {sub lance }}}
$$

Where

$K^{\prime}$ : hydrogen yield of the additions performed after sub-lance measurement.

$K^{\prime}$ is also a parameter of the model. The maximum mass of hydrogen in the lime addition is calculated according to Equation 3.

Based on the average measured values of humidity in the coolants, the maximum mass of hydrogen in the coolants is also calculated.

The hydrogen content after the pick-up from these additions is then calculated as:

$$
\% H_{i}=\% H_{\text {min }}+K^{\prime} \sqrt{\% C_{\text {sub lance }}}\left(\Delta H_{\text {lime }}+\sum \Delta H_{\text {coolants }}\right)
$$

\subsection{Hydrogen removal by combined blowing (post sub-lance)}

After the sub-lance measurement, we assume oxygen blowing and submerged blowing will promote hydrogen removal as before the sub-lance measurement. We assume that this removal is mass transport controlled. Furthermore, we assume that the equilibrium hydrogen content in the metal would be the same achieved just before the sub-lance measurement, i.e. $\% H_{\min }$. Thus, the flux of hydrogen will be expressed as:

$$
j_{H}=k_{\text {post sub }}\left(\% H\left(t_{\text {post sub }}\right)-\% H_{\text {min }}\right)
$$

Where:

$t_{\text {post sub: }}$ blow time after resuming full blow after sub-lance measurement (s);

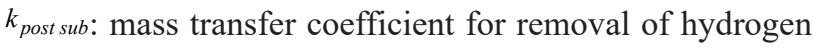
by top blow, $\mathrm{CO}$ evolution and bottom blowing.

Upon the performance of a mass balance over the liquid metal:

$$
\ln \left(\frac{\% H\left(t_{\text {post sub }}\right)-\% H_{\text {min }}}{\% H_{i}-\% H_{\min }}\right)=-\frac{100 A k_{\text {post sub }}}{W_{\text {steel }}} t_{\text {post sub }}
$$

Where:

$A k_{\text {post sub: product of effective area and mass transfer coefficient }}$ and is a parameter of the model;

$\% H_{i}$ : value calculated after post sub-lance additions, according to Equation 9;

$\% H_{\min }$ : value discussed in item 4.1 .

\subsection{Hydrogen pickup from tapping additions}

The materials added during tapping are aluminium, lime, coke, ferromanganese, ferrosilicon and synthetic slags.

The hydrogen yield of the additions performed during tapping was divided into two factors: $K^{\prime \prime}$ for coke additions and $K^{\prime \prime \prime}$ for other additions. These are also parameters of the model.

The maximum hydrogen content in the lime addition during tapping was calculated using Equation 3.

The mass of hydrogen in coke additions is calculated according to Equation 4. Based on the average measured values of humidity in the ferromanganese alloys, the maximum mass of hydrogen in the ferromanganese alloys are also calculated. Other additions were not considered relevant sources based on the statistical analysis.

The hydrogen content after the pick-up from tapping additions is then calculated as:

$$
\% H_{\text {tap }}=\% H\left(t_{\text {post sub }}\right)+K^{\prime \prime} \Delta H_{\text {coke }}+K^{\prime \prime}\left(\Delta H_{\text {lime }}+\Delta H_{\text {FeMn }}\right)
$$




\subsection{Hydrogen pickup from air during tapping}

The absorbed hydrogen during tapping was calculated assuming that the volume of gas entrained in the metal during tapping is proportional to the energy of the metal coming into the ladle as discussed in Section 3. We used an approximate factor derived from the concepts of [55-57]. Thus, the hydrogen absorbed during tapping is calculated as

$$
\% H_{\text {end tap }}=\% H_{\text {tap }}+K_{\text {tap }} G\left(\% H_{e q}^{\text {air }}-H_{\text {tap }}\right)
$$

Where,

$\% H_{\text {end tap }}$ : final hydrogen content at the end of the tapping operation;

$\% H_{\text {tap}}$ : hydrogen content in the metal considering the final content in the converter plus the result of the tapping additions (Item 4.4);

$\% H_{e q}^{a i r}$ : hydrogen dissolved in iron in equilibrium with the air humidity and oxygen in deoxidation, limited by the maximum solubility of hydrogen in iron at tapping temperature;

$G$ : term proportional to energy of tapping, calculated as $g V_{\text {steel }}^{2} t_{\text {tap }}\left(h_{i}-h_{f}\right)$ where

$g$ : gravitational constant $\left(\mathrm{m} / \mathrm{s}^{2}\right)$;

$V_{\text {steel }}$ : average rate of tapping $(\mathrm{t} / \mathrm{s})$;

$t_{\text {tap }}$ : total tapping time (s);

$h_{i}$ : height measured from the tap hole to the bottom of the empty ladle $(\mathrm{m})$;

$h_{f}$ : height measured from the tap hole to the top of the full ladle (m);

$K_{\text {tap }}$ : constant of the model.

\subsection{Fitting of the model coefficients}

The constants of the model were adjusted with data from 403 heats cast from May to July 2020 using the Solver routine in Excel $®$. The objective was to find parameter models that minimize the sum of the square of the differences between measured hydrogen and predicted hydrogen. As the model is non-linear, there is some dependence on initial values and it is not always guaranteed that the Solver solution will not be a local minimum [63]. For this reason, different start values were used for the model parameters, to ensure that the final parameters were a stable solution. The parameters obtained using this procedure were:

$$
\begin{aligned}
& H_{\text {min }}=0.5 \mathrm{ppm} ; A k_{\text {post sub }}=88.0 ; K_{\text {tap }}=0.487 \times 10^{-3} \\
& K^{\prime}=0.235 ; K^{\prime \prime}=0.344 ; K^{\prime \prime \prime}=0.816
\end{aligned}
$$

Figure 5 presents the model calculated values of hydrogen at the different steps of the process.

The correlation between calculated and measured hydrogen is shown in Figure 6. A correlation coefficient $r^{2} \cong 0.71$ was obtained. The model deviates from the $y=x$ line. These results are considered a reasonable correlation for an industrial-scale model, in special in view of the absence of intermediate measurements of hydrogen content, which could make possible a better adjusted of the individual stages of the model.

Including effects of the ladle heating stage when there is Ar stirring for each heat in the LTS did not improve the results of the model. Furthermore, no correlation with steel grade was found. When heats subjected to longer argon bottom blowing ( $\geq 50 \%$ of blow time) were analyzed separately, they showed a better fit to the model, but no significant difference in the model parameters. This is an interesting topic to for future work.

\subsection{Foreseen model application}

In order to reduce costs of hydrogen measurement sensors currently used in all heats in AHF route different cut-off values were evaluated for the model, with the aim of identifying heats with $6 \mathrm{ppm}$ of more hydrogen at the AHF. A cut-off value of $\mathrm{H}<4 \mathrm{ppm}$ was selected. The results of using this cut-off were calculated and are shown in Table 1. The results indicate that no heat with more than $6 \mathrm{ppm}$ of hydrogen would proceed in the process, with

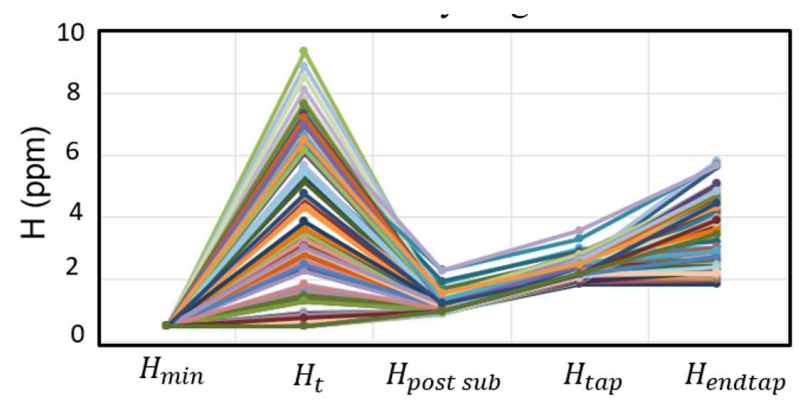

Figure 5. Calculated values of hydrogen at the different steps of the process, using the adjusted model. Steps are in accordance to Figure 4.

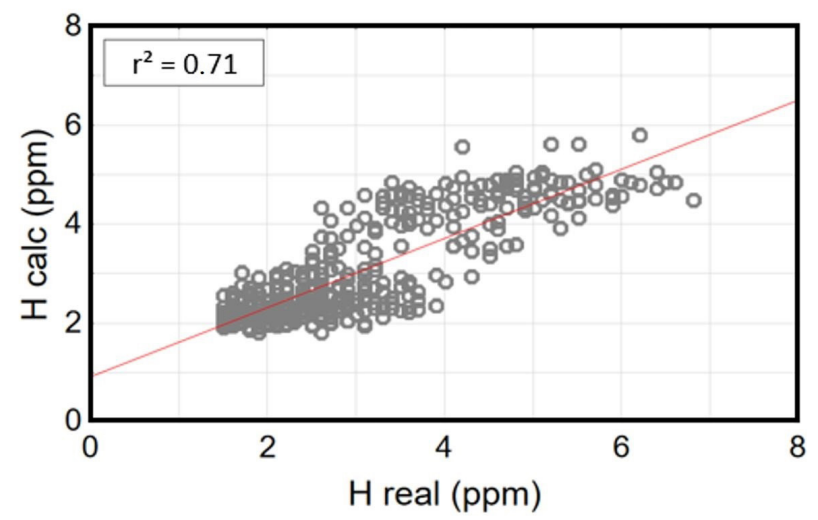

Figure 6. Correlation between calculated and real hydrogen in 403 industrial heats.

Table 1. Model success index

\begin{tabular}{lccc}
\hline & $\begin{array}{c}\text { H real }<4 \\
\mathbf{p p m}\end{array}$ & $\begin{array}{c}\mathbf{6 p p m}>\mathbf{H} \text { real } \\
\mathbf{2 4} \mathbf{p p m}\end{array}$ & $\begin{array}{c}\mathbf{H} \text { real } \geq 6 \\
\mathbf{p p m}\end{array}$ \\
\hline $\mathrm{H}$ calc $<4 \mathrm{ppm}$ & $95 \%$ & $5 \%$ & $0 \%$ \\
\hline
\end{tabular}


the risk of breakout if the cut-off value was selected at a calculated value of $4 \mathrm{ppm}$. Furthermore, only $5 \%$ of the heats would still be sampled, since they would have a measured value between 4 and $6 \mathrm{ppm}$. This means that, using the model with a cut-off of calculated 4ppm hydrogen content it is possible to reduce in $95 \%$ the use of hydrogen measurement sensors.

\section{Conclusions}

The control of hydrogen to prevent problems in continuous casting at Ternium is essential. Thus, the possible sources of hydrogen in steel in Ternium meltshop were identified and reviewed. A statistical analysis pointed the sources of hydrogen in steel that are possibly more relevant at the Ternium melt-shop. Combined blowing and $\mathrm{CO}$ evolution in converter is enough to eliminate the moisture that enters in the converter by scrap and fluxing additions at the beginning of the heat. Additions made after sub-lance measurement were observed to be the main sources of hydrogen pickup into steel in the converter. Although combined blowing after sub-lance measurement contributes to reduce the hydrogen pickup from these additions, it is usually not sufficient to reduce it to the level of heats in which no adjustments after sub-lance measurement are made. The tapping operation and additions during tapping contribute to hydrogen pickup in steel. The slag layer formed after tapping probably protects the steel from pickup from atmospheric moisture during the transport of the ladle to the later stages of steelmaking. The moisture of the ladle refractory has no influence in the final hydrogen content, which means that the ladle heating methods are suitable. As Ternium plant is located in a region where high relative humidity is almost constant during the year, no correlation of hydrogen to partial atmospheric water vapour pressure on could be observed. Evidently, the high humidity is a challenge to keeping all raw materials and refractories dry to control hydrogen pickup.

A model was formulated to calculate the expected hydrogen content at the arrival of the heat at the aluminium heat facility, where currently $100 \%$ of heats are analysed for dissolved hydrogen. The results of model shown a correlation coefficient of $r^{2} \cong 0.71$ to the measured values. It is suggested that, if a cut-off value of $4 \mathrm{ppm}$ calculated by the model for hydrogen analysis was adopted, $95 \%$ of the heats would not need to be analysed without increasing the risk of breakouts in the casting machine.

\section{Acknowledgements}

The authors thank Ternium for the support during the performance of this work and for the authorization to publish these results. This study was financed in part by the Coordenação de Aperfeiçoamento de Pessoal de Nível Superior - Brasil (CAPES) - Finance Code 001.

\section{References}

1 Turkdogan E. Principles of steelmaking. London: The Institute of Materials; 1996.

2 Gaye H. Inclusion formation in steels. In: Cramb A, ed. The making, shaping and treating of steel, casting volume. 11th ed. Chap. 3. Pittsburgh: AIST; 2003.

3 Hino M, Ito K. Thermodynamic data for steelmaking. In: The 19th Committee for Steelmaking; 2010; Tohoku. Sendai: Tohoku University Press; 2010.

4 Glueckauf E, Kitt GP. The hydrogen content of atmospheric air at ground level. Quarterly Journal of the Royal Meteorological Society. 1957;83(358):522-528.

5 Epstein H, Chipman J, Grant NJ. Hydrogen in steelmaking practice. JOM. 1957;9(4):597-608.

6 vom Ende H, Liestmann WD. The hydrogen content in the manufacturing of oxygen converter steel. Stahl und Eisen. 1965;85(3):117-124.

7 Kerlie WL, Richards JH. Origin and elimination of hydrogen in basic open-hearth steels. JOM. 1957;9(12):15411548 .

8 Verdan L, Avillez RR, Costa e Silva A. Hydrogen issues in steel processing- a preliminary approximation. In: XLV CALPHAD; 2016; Awaji Island, Japan. Japan: JSPS; 2016. p. 163.

9 Uda M, Dan T, Ohno S. Effect of hydrogen on blowhole formation in pure iron during solidification. Tetsu To Hagane. 1976;62(1):62-71.

10 Barraclough K. The significance of hydrogen in steel manufacture. Murex Review. 1954;1:305.

11 Costa e Silva A. Applications of multicomponent databases to the improvement of steel processing and design. Journal of Phase Equilibria and Diffusion. 2017;38(6):916-927.

12 Ueshima Y, Mizoguchi T, Kajitani T. Hydrogen-induced sticker breakouts in continuous casting of steel: chemical reactions between ambient atmosphere, molten flux, molten steel and solidified shell. In: Molten Slags; 2012; Beijing, China. Beijing; 2012. p. 8. 
13 Abraham S, Chen S, Asante J, Souza CD. Hydrogen and nitrogen control and breakout warning model for casting non-degassed steel. Iron and Steel Technology. 2010;7(10):54-64.

14 Mizukami H, Hara M, Shirai Y, Watanabe T. Generation of hydrogen gas from solidified shell surface at initial stage of solidification of carbon steel. ISIJ International. 2004;44(10):1714-1719.

15 Sahoo PP, Rout BK, Palai P. Mechanism and control of hydrogen induced abnormal sticky behavior in slab casting mould. ISIJ International. 2015;55(5):993-999.

16 Susaki K, Serra JG, Almeida EN, Botelho AH. Evolução dos processos de refino e lingotamento de aços microligados e tratados com CaSi na CSN. In: Anais do XXXVI Seminário de Fusão, Refino e Solidificação dos Metais; 2005; Vitória, ES. São Paulo: ABM; 2005.

17 Scott TE, Troiano AR. Hydrogen and segregates in flaking. JOM. 1959;11(9):619-622.

18 Pressouyre GM. Current solutions to hydrogen problems in steels. In: Interrante CG, Pressouyere GM, editors. Proceedings of the 1st International Conference in Current Solutions to Hydrogen Problems in Steels; 1982; Washington. Materials Park: ASM International; 1982. p. 55.

19 Costa e Silva A. Using computational thermodynamics to understand the evolution of solidification segregation during steel processing. Journal of Phase Equilibria and Diffusion. 2020;41(4):522-531.

20 Wasim M, Djukic MB. Hydrogen embrittlement of low carbon structural steel at macro-, micro- and nano-levels. International Journal of Hydrogen Energy. 2020;45(3):2145-2156.

21 Steiner JE, Murphy EL. Williams RD. Hydrogen and Flaking After 40 Years of Vacuum Degassing. In: Nisbett E, Melilli A, editors. Steel forgings: second volume, ASTM STP 1259. West Conshohocken: American Society for Testing and Materials; 1997.

22 Plessers J, Maes R, Vangelooven E. Ein neues Tauchsystem für die schnelle Bestimmng von Wasserstoff in flüssigem Stahl. Stahl und Eisen. 1988;108:451-455.

23 Takaishi S, Komai T, Murata H, Hiromoto K, Sekihara H. Behavior of hydrogen in steel in the steel-making and strand casting processes. Tetsu To Hagane. 1978;64(9):1343-1352.

24 Henriques BR. Estudo da incorporação do hidrogênio no aço líquido [dissertação]. Ouro Preto: UFOP; 2010.

25 Bragança SR, Hohemberger JM, Vicenzi J, Marques CM, Basegio T, Correia Lima ÁN, et al. Hydrogen potential sources in refractory materials during steel casting. Steel Research International. 2006;77(6):400-403.

26 Correa RS, Carvalho DAG, Cerchiari BS, Ribeiro JC, Moura EL. Utilização de redes neurais para prever teor de hidrogênio em aços. In: Anais do $50^{\circ}$ Seminário de Aciaria, Fundição e Metalurgia de Não-Ferrosos; São Paulo; 2019. São Paulo: ABM; 2019. p. 264-273.

27 Braga BM, Tavares RP. Mathematical model for prediction of hydrogen pick-up of liquid steel during filling of a continuous casting tundish. Metallurgical Research \& Technology. 2018;115(4):409.

28 Fruehan R, Misra S. Hydrogen and nitrogen control in ladle and casting operations. Pittsburgh: Department of Materials Science and Engineering, Carnegie Mellon University; 2005. Report No.: DOE Contract DE-FC3697ID13554.

29 Poirier J. A review: influence of refractories on steel quality. Metallurgical Research \& Technology. 2015;112(4):410-1-410-20.

30 Lingras AP. Hydrogen control in steelmaking. In: Electric Furnace Conference; 1982. Iron \& Steel Society; 1982. p. 133-143.

31 Manocha S, Ponchon F. Management of Lime in Steel. Metals. 2018;8(9):686.

32 Fruehan R, editor. Making, shaping, and treating of steel, steelmaking and refining volume. 11th ed. Pittsburgh: AIST Steel Foundation; 1998.

33 Silveira RC, Almeida AM, Fernandes A. A presença do hidrogênio nos processos de produção do aço. In: IV Congreso Ferroaleaciones; 1988; Salvador de Bahía, Brasil. Santiago, Chile: Instituto Latinoamericano del Fierro y el Acero; 1988. p. 11-16.

34 Ootsuka M, Yamamoto S, Nakagawa K, Kouroki S, Iwata K, Nagahata T. The successive hydrogen concentration control in molten steel by direct hydrogen measuring system. ISIJ International. 1996;36(Suppl):S97-S100.

35 Predel H. Petroleum coke. In: Schwarz W, Schossig J, Rossbacher R, Höke H, editors. Ullmans's enclyclopedia of industrial chemistry. Weinheim: Wiley-Interscience; 2000. 
36 Jha KN, Sardar MK, Jha NN, Chakraborty S. Hydrogen control during steel making for medium carbon wheels. Scandinavian Journal of Metallurgy. 2003;32(6):296-300.

37 Jung I-H. Thermodynamic modeling of gas solubility in molten slags-water. ISIJ International. 2006;46(11):15871593.

38 Richardson FD. Physical chemistry of melts in metallurgy. London: Academic Press; 1974.

39 Weather \& Climate. 2020 [cited 2020 Nov 20]. Available at: https://weather-and-climate.com

40 Belton GR, Hunt RW. How fast can we go? The status of our knowledge of the rates of gas-liquid metal reactions. Metallurgical Transactions. B, Process Metallurgy. 1993;24:241-258.

41 Boorstein WM, Pehlke RD. Kinetics of solution of hydrogen in liquid iron alloys. Transactions of the Metallurgical Society of AIME. 1969;245:1843.

42 Small WM, Radzilowski RH, Pehlke RD. Kinetics of solution of hydrogen in liquid iron, nickel, and copper containing dissolved oxygen and sulfur. Metallurgical Transactions. 1973;4(9):2045-2050.

43 Suzuki K, Taniguchi K. Kinetics of the hydrogen desorption and absorption of molten steel. Tetsu To Hagane. 1976;62(6):605-613.

44 Sasaki Y, Belton GR. Steady-state studies of the reactions of $\mathrm{H}_{2} \mathrm{O}-\mathrm{CO}$ and $\mathrm{CO}_{2}-\mathrm{H}_{2}$ mixtures with liquid iron. Metallurgical and Materials Transactions. B, Process Metallurgy and Materials Processing Science. 1998;29(4):829836.

45 Nebosov Y, Sukharev SV, Kazakov SV. Kinetics of hydrogen removal in the gas phase in ladle vacuum treatment. Steel in Translation. 2007;37(7):572-574.

46 Bannenberg N, Bergmann B, Gaye H. Combined decrease of sulphur, nitrogen, hydrogen and total oxygen in only one secondary steelmaking operation. Steel Research. 1992;63(10):431-437.

47 Kleimt B, Kohle S, Johann KP, Jungreithmeier A, Molinero J. Dynamic process model for denitrogenation and dehydrogenation by vacuum degassing. Scandinavian Journal of Metallurgy. 2000;29(5):194-205.

48 Steneholm K, Andersson M, Tilliander A, Jönsson PG. Removal of hydrogen, nitrogen and sulphur from tool steel during vacuum degassing. Ironmaking \& Steelmaking. 2013;40(3):199-205.

49 Gaye H, Huin D, Bannenberg N, Bergmann B. Modeling of vacuum tank degassing of liquid steel. Le Vide. Les Couches Minces. 1992;261:55-57.

50 Kempken J. Entwicklung eines Simulationsmodells zur Beschreibung der Stichstoffbewegung im Sauerstoffblasprozess [dissertation]. Clausthal-Zellerfeld: TU Clausthal; 1994.

51 Kempken J, Pluschkell W. Simulationsrechnungen zur Entwicklung der Stickstoff im LD-Prozess. Stahl und Eisen. 1995;115(8):67-74.

52 Jun N, Take H, Nakanishi K, Yamamoto T, Tachibana R, Iida Y, et al. Metallurgical characteristics of combinedblown converters. Kawasaki Steel Technical Report. 1982;6:12-20.

53 Denier G. Aciéries de conversion: contexte et aspects théoriques. Techniques de l'Ingénieur. 2018 Apr 10.

54 Denier G, Grosjean JC, Kuhnast J. Protection des tuyères LWS par du $\mathrm{CO}_{2}$ liquide à l'acierie d'Hagondange. Revue de Metallurgie - CIT. 1980;77(4):299-305.

55 Choh T, Iwata K, Inouye M. Estimation of air oxidation of teeming molten steel. ISIJ International. 1983;23(7):598607.

56 Asai S, Muchi I. Mathematical model of nitrogen absorption at tapping from LD converter. Tetsu To Hagane. 1967;53(7):746-747. http://dx.doi.org/10.2355/tetsutohagane1955.53.7_746.

57 Okayama A, Higuchi Y. A water model experiment on gas absorption during tapping. Tetsu To Hagane. 2016;102(11):607-613.

58 Okayama A, Nakamura O, Higuchi Y. Analysis of plunging pool formation and gas absorption phenomenon during tapping. ISIJ International. 2018;58(4):677-685.

59 Darken LS. Kinetics of metallurgical processes. In: Derge G, editor. Basic open hearth steelmaking. Pittsburgh: AIME; 1951.

60 Darken L, Gurry R. Physical chemistry of metals. New York: McGraw-Hill; 1953.

61 Levenspiel O. Chemical reaction engineering. 3rd ed. New York: Wiley; 1999.

62 Taylor R. Interpretation of the correlation coefficient: a basic review. Journal of Diagnostic Medical Sonography. 1990;6(1):35-39. 
A predictive model for hydrogen content in steel in non-degassed heats

63 FrontLine Solvers. 2020 [cited 2020 Nov 22]. Available at: https://www.solver.com/standard-excel-solverlimitations-nonlinear-optimization

Received: 26 Nov. 2020

Accepted: 8 Jan. 2021 